This item was submitted to Loughborough's Research Repository by the author.

Items in Figshare are protected by copyright, with all rights reserved, unless otherwise indicated.

\title{
Comparing discrete-event simulation and system dynamics: users' perceptions
}

PLEASE CITE THE PUBLISHED VERSION

http://dx.doi.org/10.1057/palgrave.jors.2602566

PUBLISHER

Palgrave Macmillan @ Operational Research Society Ltd

VERSION

AM (Accepted Manuscript)

LICENCE

CC BY-NC-ND 4.0

REPOSITORY RECORD

Tako, Antuela A., and Stewart Robinson. 2019. "Comparing Discrete-event Simulation and System Dynamics: Users' Perceptions”. figshare. https://hdl.handle.net/2134/9620. 
This item was submitted to Loughborough's Institutional Repository (https://dspace.lboro.ac.uk/) by the author and is made available under the following Creative Commons Licence conditions.

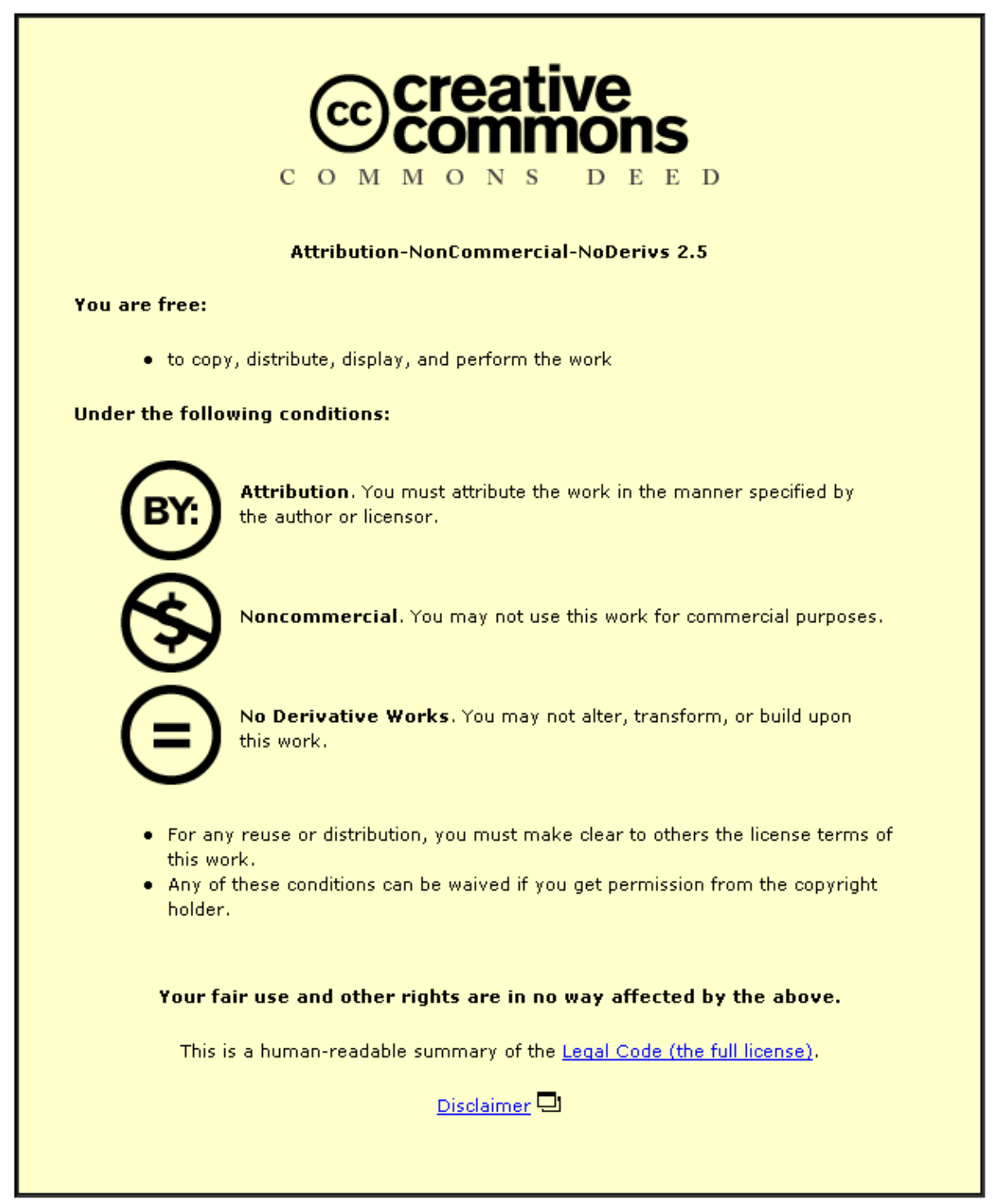

For the full text of this licence, please go to: http://creativecommons.org/licenses/by-nc-nd/2.5/ 


\title{
Comparing discrete-event simulation and system dynamics: Users' perceptions
}

\author{
Antuela A. Tako*, Stewart Robinson \\ Warwick Business School, University of Warwick, Coventry, UK
}

\begin{abstract}
This paper is the first of its type in that it provides an empirical study comparing the two simulation approaches of Discrete-Event Simulation (DES) and System Dynamics (SD). Prior comparison work is limited and mostly based on the authors' personal opinions. In the present work the comparison is based on managers' (executive MBA students) perceptions of two simulation models of the same problem, one in DES and one in SD. The study found that there is no significant difference from the users' point of view between DES and SD in terms of model understanding and model usefulness. Some minor differences were found in terms of complexity and validity of the models, and the model results. The implications of our findings regarding model understanding, model complexity, model validity, model usefulness and model results are discussed.
\end{abstract}

Keywords: Simulation, Discrete-Event Simulation, System Dynamics, Model use

\section{Introduction}

Discrete-Event Simulation (DES) and System Dynamics (SD) are two popular simulation approaches used in Operational Research (Pidd, 2004). DES models a system as a set of individual entities moving through a series of queues and activities in discrete time. SD models a system as a set of stocks and flows which are adjusted in pseudo-continuous time. It is clear that both approaches can be used to support management learning and decision-making (Robinson, 2004). While some argue that DES and SD are quite separate simulation approaches (Brailsford and Hilton, 2001), others see them as complementary to one another (Morecroft and Robinson, 2005).

\footnotetext{
* Correspondence: Warwick Business School, University of Warwick, CV4 7AL, Coventry, E-mail addresses: a.tako@warwick.ac.uk (A. Tako) and stewart.robinson@warwick.ac.uk (S. Robinson)
} 
Work on the comparison of the two simulation approaches is limited, consisting mainly of some conference papers. The few comparative studies that can be found in the literature are mostly based on the authors' personal opinions (Brailsford and Hilton, 2001; Morecroft and Robinson, 2005). To date there has been no empirical study reported that provides an evidence base for a comparison of the two approaches.

The current study aims to address this dearth of evidence by identifying the significant differences and similarities between the two simulation approaches empirically. In this paper the focus is on model use and more specifically we look at users' opinions about two simulation models, one in DES and the other in SD. A separate study is being undertaken on the model development process for DES and SD. The approach taken is to present managers (executive MBA students) with two models of the same problem situation and to evaluate their perceptions on: model understanding, complexity, validity, learning and model results. For the models a public sector problem, the UK prison population, was chosen. The key contribution of the study is to provide empirical evidence on the similarities and differences between DES and SD from a user's perspective.

The paper starts by reviewing existing work on the comparison of DES and SD model use. The empirical study is then presented in which the case study, the simulation models, the subjects of the study (executive MBA students), the model use sessions and the questionnaire are described. The results across a range of factors are given, before discussing the implications of the findings from the point of view of the modeller and the manager. Some limitations of the study are discussed and potential further work is identified.

\section{Existing work on the comparison of DES \& SD model use}

This section reviews the existing literature on the comparison of two simulation approaches DES and SD, focusing on comments made regarding the aspect of model use and understanding. The comparisons are summarised under the following headings: understanding, complexity, model validity, model usefulness and model results.

The literature on the comparison of DES and SD is scarce. As a general comment, work on the comparison of the two simulation techniques consists mostly of generally accepted statements (Brailsford and Hilton, 2001; Morecroft and Robinson, 2005). 
Furthermore, comparisons tend to be biased towards either the DES or SD approach (Brailsford and Hilton, 2001; Morecroft and Robinson, 2005). We have not yet identified any empirical evidence certifying statements made about the use of DES and SD models.

\subsection{Understanding}

Both simulation approaches can be used to understand how systems behave over time (Sweetser, 1999). However, contradictory statements are made regarding the level of understanding that users can gain from using these models. According to Brailsford and Hilton (2001), DES models are transparent to the clients. Animation and on-screen displays can provide useful insights about the model's structure. Lane (2000) argues that while DES models are convincing to the client, users do not necessarily understand the underlying mechanics of the model. On the other hand, Lane (2000) states that SD models are transparent and compelling to the client. Randers (1980), in a comparison of system dynamics and modelling used for prediction (applicable to DES models), rated SD as having a higher capacity to increase clients' (users') understanding and also their learning, calling it "insight generation capacity". However, a disadvantage related to SD models is that there is no animation and the user has to rely on graphs and numerical displays (Sweetser, 1999).

\subsection{Complexity}

Looking at both simulation approaches in terms of model complexity, DES is more concerned with detailed complexity, while SD with dynamic complexity (Lane, 2000). This is due to their inherent features, where DES can model great complexity and detail, while SD represents the aggregate picture of the system. In SD, a model's behaviour is determined by the feedback structure and dynamic complexity arising from the influences among endogenous variables. In DES, complexity is the result of multiple random processes and the endogenous structure of the system (Lane, 2000; Morecroft and Robinson, 2005). It is generally claimed that DES follows an open loop structure and feedback is not modelled (Coyle, 1985). It has been argued, however, that feedback is involved in DES models but that it is not made explicit to the users (Sweetser, 1999; Lane, 2000; Morecroft and Robinson, 2005). 


\subsection{Model Validity}

We consider model validity in terms of model use as a measure of the user's confidence in the model (credibility). Credibility is seen in terms of representativeness (Robinson, 2004, p. 231), confidence in the results and confidence in using the model for decision making (Robinson, 2004, p. 214). Randers (1980) rates SD models as highly representative, compared to a predictive model (including DES). It is generally accepted that both simulation approaches are concerned with building models which are representative of reality, providing confidence in the results and in decision-making. Indeed, Akkermans (1995) argues that in most cases DES and SD can represent the real world with equal validity.

\subsection{Model Usefulness}

Another important factor mentioned in the literature when comparing DES and SD is model usefulness. The concept of learning from using simulation models is widely mentioned in the SD literature (Forrester, 1961; Morecroft and Sterman, 1994). Business flight simulators are considered to be appropriate "learning laboratories" that can help managers gain insights about their businesses operations. On the contrary, DES models are seen mostly as the domain of simulation experts and are used less as learning tools by non-technical managers (Sweetser, 1999). However, these are statements made by modellers without considering users' opinions about specific models.

Another facet of model use is the nature of problems modelled by each simulation technique, "strategic" vs. "tactical/operational". It is generally accepted that while DES takes an analytic view, SD takes a holistic view of a system's performance. SD focuses mainly on strategic policy analysis, while DES tends to study operational, tactical problems (Sweetser, 1999; Lane, 2000). DES models generally have a narrow focus (Sweetser, 1999) and are usually applied at an operational, tactical level (Brailsford and Hilton, 2001).

Both simulation approaches can be used as tools to facilitate the communication of ideas in group discussions (Robinson, 2004). Brailsford and Hilton (2001) state that DES software provide animation and graphics facilities, features "very useful for communication with clients". 


\subsection{Model Results}

Mak (1993) points out that SD models provide a full picture of a system in the simulated period. In SD, point predictions are rarely made (Sweetser, 1999). In DES modelling emphasis is given to point prediction, with outputs providing statistically valid estimates of the system's performance measures (Sweetser, 1999, Brailsford and Hilton, 2001; Law, 2007). DES models provide a wide range of outputs, principally of a quantitative nature. Additionally, the interpretation of DES model results requires some statistical analysis. The outputs of one simulation run represent only one possible outcome due to the randomness in the model. For this reason, a practice used often in DES is running many iterations of the model with the use of different random number seeds (Pidd, 2004; Robinson, 2004). In order to make a proper analysis of the DES output, the model user should have some statistical background (Sweetser, 1999, Brailsford and Hilton, 2001).

When looking at model results, due to the inherent features of the two modelling techniques, different aspects of the model can be picked up by the users. DES models contain random variables and are stochastic in nature, while SD systems generally depict deterministic behaviour. Therefore, SD model results are considered as a source of understanding the reasons that cause changes in the system's performance, resulting from counter intuitive effects of the system's structural behaviour (Morecroft and Robinson, 2005). Meanwhile DES modellers and model users, are less interested in the events that actually cause these changes and focus more on the numerical results (Sweetser, 1999).

\subsection{Summary of Previous Comparison Work}

The opinions stated in the literature comparing DES and SD are summarised in table 1. There appears to be a general level of agreement on the nature of the differences. It should be noted, however, that a contrary view has been expressed by Akkermans (1995). He considered different types of modelling in business (DES, SD and spreadsheets) for real case scenarios. He claimed that as part of the model building process, the choice of modelling approach is not highly important. He also adds that the clients are usually not concerned about the choice of the simulation software used in a modelling project. If correct, this suggests that the differences may not be as clear cut as indicated in table 1. 
Table 1: Summary of literature comparison of DES \& SD model use

Model Use

Model Understanding

\begin{tabular}{|l|l|}
$\begin{array}{l}\text { Understanding } \\
\text { (parts of) the model }\end{array}$ & $\begin{array}{l}\text { The client does not understand the } \\
\text { underlying mechanics. }\end{array}$ \\
\hline Animation & $\begin{array}{l}\text { Animation and graphic tools help } \\
\text { model understanding }\end{array}$ \\
\hline
\end{tabular}

Complexity

Level of detail

\begin{tabular}{|l|l|l}
\hline Feedback & Feedback is not explicit & Fe \\
\hline
\end{tabular}

Model Validity

\begin{tabular}{|l|l|l}
\hline Credibility & \\
\hline
\end{tabular}

DES

Models (links \& flows) are transparent to the client. No animation. Visual display of model aids model understanding.

Model Usefulness

\begin{tabular}{|c|c|c|}
\hline Learning tool & $\begin{array}{l}\text { DES models are less used as } \\
\text { learning tools. }\end{array}$ & $\begin{array}{l}\text { SD models, so-called "learning } \\
\text { laboratories", enhance users" } \\
\text { learning. }\end{array}$ \\
\hline Strategic thinking & $\begin{array}{l}\text { DES models are mostly used in } \\
\text { solving operational/tactical issues }\end{array}$ & SD models aid strategic thinking. \\
\hline $\begin{array}{l}\text { Communication } \\
\text { tool }\end{array}$ & \multicolumn{2}{|c|}{$\begin{array}{c}\text { Both DES and SD models are seen as good communication tools and } \\
\text { facilitate communication with the client }\end{array}$} \\
\hline \multicolumn{3}{|l|}{ Model Results } \\
\hline Nature of results & $\begin{array}{l}\text { DES provides statistically valid } \\
\text { estimates of system's performance. } \\
\text { Results aid instrumental learning. }\end{array}$ & $\begin{array}{l}\text { SD model results provide a full } \\
\text { picture of the system. Results aid } \\
\text { conceptual learning. }\end{array}$ \\
\hline $\begin{array}{l}\text { Interpretation of } \\
\text { results }\end{array}$ & $\begin{array}{l}\text { More difficult, requires users to have } \\
\text { statistical background. }\end{array}$ & $\begin{array}{l}\text { Outputs are easily interpreted, little } \\
\text { or no statistical analysis is required. }\end{array}$ \\
\hline $\begin{array}{l}\text { Results } \\
\text { observation }\end{array}$ & $\begin{array}{l}\text { Randomness/variation of results is } \\
\text { explicit. }\end{array}$ & $\begin{array}{l}\text { Generally deterministic results, } \\
\text { which convey causal relationships } \\
\text { between variables. }\end{array}$ \\
\hline
\end{tabular}

\section{Methods and research design}

The current empirical study aims to confirm/refute the statements found in the literature. The aim here is to empirically identify how different the two simulation techniques are from the users' point of view. More specifically our objective is to assess and compare the two simulation techniques in respect to the following criteria:

1. Understanding derived from using equivalent DES and SD simulation models.

2. Perceived complexity of equivalent DES and SD simulation models.

3. Credibility in using equivalent DES and SD simulation models.

4. Perceived usefulness of equivalent DES and SD simulation models in terms of learning, strategic thinking and communication of ideas.

5. Result interpretation of equivalent DES and SD models outputs. 
In terms of this study an "equivalent model" is a typical DES or SD model of the same problem situation.

Based on the literature discussed in section 2 above, we expect users to find SD and DES models equally credible for giving answers to a problem situation and equally helpful as communication tools. However, we expect to find differences in users' opinions about model understanding, model complexity, interpretation of model results and the models' role in learning and strategic thinking.

The empirical study took the form of two separate sessions delivered to two different groups of executive MBA students at Warwick Business School as part of the "Modelling and Analysis for Management" core module (Robinson et al., 2003). The experimental factor was the simulation model used. One group used a DES model and the other group a SD model. We asked the participants to use these models working in groups with the view to giving them hands-on experience. Their task was to provide answers as to how to solve the problem presented in the case study. At the end of the sessions the participants evaluated the simulation models by completing a questionnaire survey.

\subsection{The case study}

Choosing an appropriate case study was considered important for the purposes of this work. The simulation models based on the case study need to be simple enough so that managers, who usually have little or no prior experience of simulation modelling, can be in a position to understand and use them for decision-making. The case study and models were designed to fit with the MBA course curriculum and requirements for a 1.5 hour session. In addition a suitable case study needs to accommodate models from both simulation techniques, so that the specific features of each technique (randomness in DES vs. deterministic models in SD, the aggregated presentation of entities in SD vs. the individual representation of entities in DES, etc.) are present in the models built.

After thoughtful consideration, a case study on the UK prison population based on Grove et al. (1998) was chosen. The prison population is a topical subject both in the UK and elsewhere (e.g. (Korporaal et al., 2000). The inherent feedback that exists in the system, with prisoners entering and returning back to prison due to re-offending (recidivism), can be uniquely represented by each simulation approach, DES and SD. DES and SD have both been used to model the prison population. DES models of the prison population have been developed by Kwak et al. (1984), Cox et al. (1987), 
Korporaal et al. (2000). A SD model has been developed in Bard (1978). Therefore, we consider the UK prison population as a suitable case study to use for this research.

The case study starts with a brief introduction to the prison population problem and draws particular attention to the issue of overcrowded prisons. An overview of the system is shown in figure 1. Two types of offenders are considered, petty and serious offenders. There are initially 76,000 prisoners in the system, of which 50,000 are petty and 26,000 serious offenders. Offenders enter the system as first time offenders and receive a sentence depending on the type of offence. Petty offenders enter the system at a higher rate, due to a higher rate of offending (on average 3,000 people/year vs. 650 people/year for serious offenders), but receive a shorter sentence length (on average 5 years vs. 20 years for serious offenders). After serving time in prison the offenders are released. A proportion of the released prisoners re-offend and go back to jail (recidivists) after on average 2 years. Petty prisoners are more likely to re-offend, $70 \%$ re-commit petty crimes and go back to jail and another $3 \%$ commit even more serious crimes and are re-convicted as serious offenders. Serious offenders represent a small percentage of the total offender population and have lower rates of recidivism. Only $30 \%$ of serious offenders re-offend and go back to jail as serious offenders after 2 years.

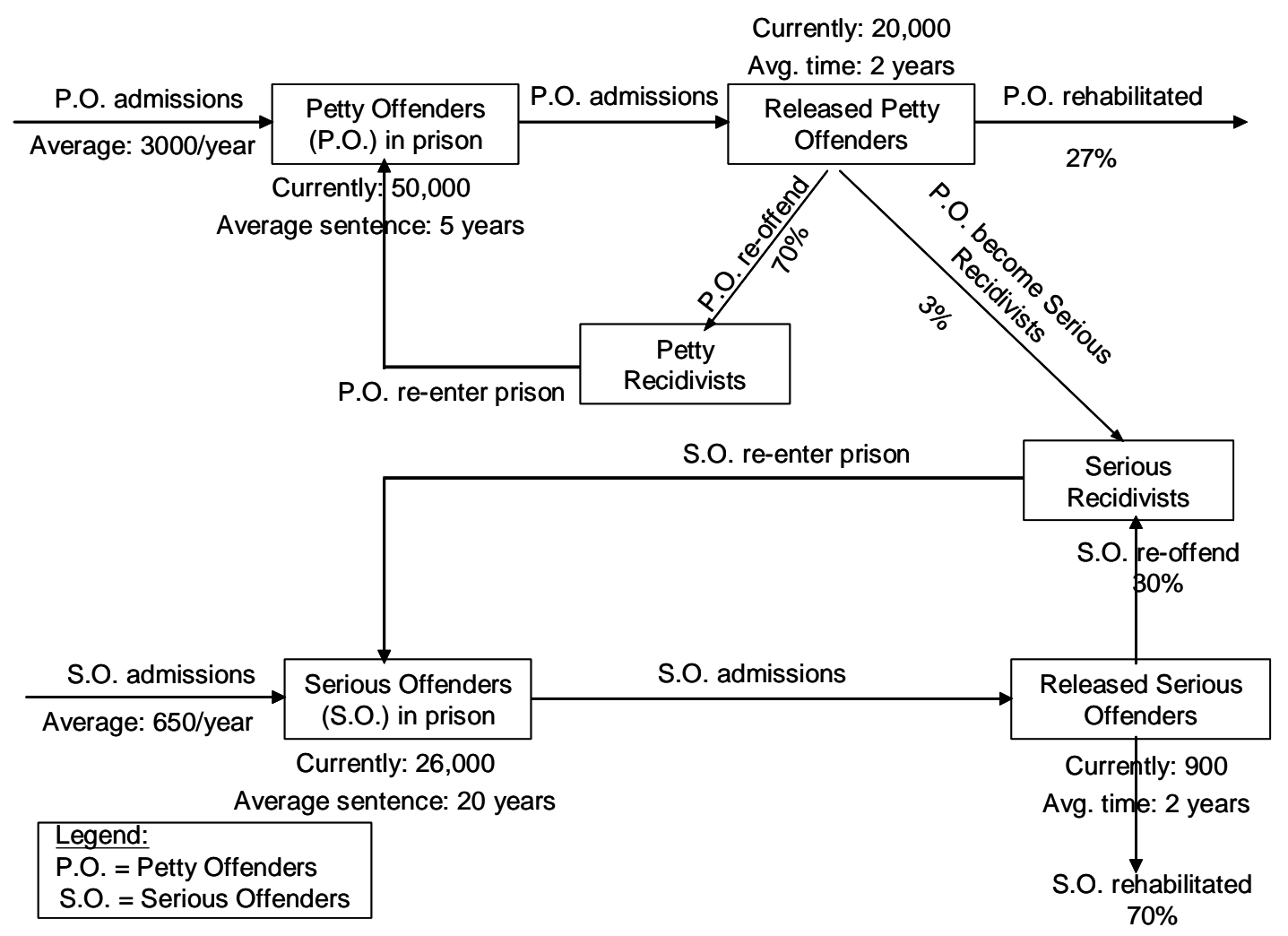

Figure 1: Overview of the prison population problem 
The case study presents the reasons for, and impacts of, the problem, followed by a set of possible alternative policies, which can be implemented in order to solve the existing problem. The problem is presented as a typical public sector resource allocation problem with an objective to improve the capacity of the criminal justice system in preventing crime and deterring its repetition, by taking into consideration the specified budget allocation. Based on the above, the case study's question is: "taking the role of a government consulting service, suggest possible policy changes to government authorities". Since both DES and SD have been used to address this issue in practice, we believe that the two techniques have a rough equivalence with respect to this objective.

\subsection{The simulation models}

Based on the case study described above a DES and a SD simulation model were built. Both simulation models are a simple representation of a prison overcrowding problem showing how the prison population evolves over time. Our main objective was to build two simple models which enable experimentation with different scenarios/policies, with the intention of using them as tools for decision making. The DES model was developed using WITNESS (www.lanner.com accessed November 2007), a powerful and versatile DES simulation package. For the SD model, Powersim Studio 2005 (www.powersim.com accessed November 2007) was used. This is a package used widely in the field of SD. Both models incorporate a user interface which enables inputs to be set and altered. Witness and Powersim are typical of the simulation software in their respective fields. Although there is some variation in the facilities in alternative packages, there is no specific reason to believe that the choice of package would have much influence on the representation of a simple model such as the prison population case used in this research (Robinson, 2008).

The simulation environment of the DES model is presented in figure 2 . The model environment includes a number of different windows which consist of, the model (the box on the left in figure 2), the input data (on the top, right-hand corner) and the model outputs (at the bottom, right-hand corner). Control buttons (i.e. run, stop, reset etc.) are included and also a window which reports the time. On the click of the run button, a window appears asking the users to choose the relevant input data according to the policy or policies chosen. The user can also access a series of graphical results by 
selecting the graphs button. These include plots of the prison population, plots of rehabilitated prisoners and plots of the recidivists over time, and also bar charts with the distribution of sentence lengths, for both petty and serious offenders.

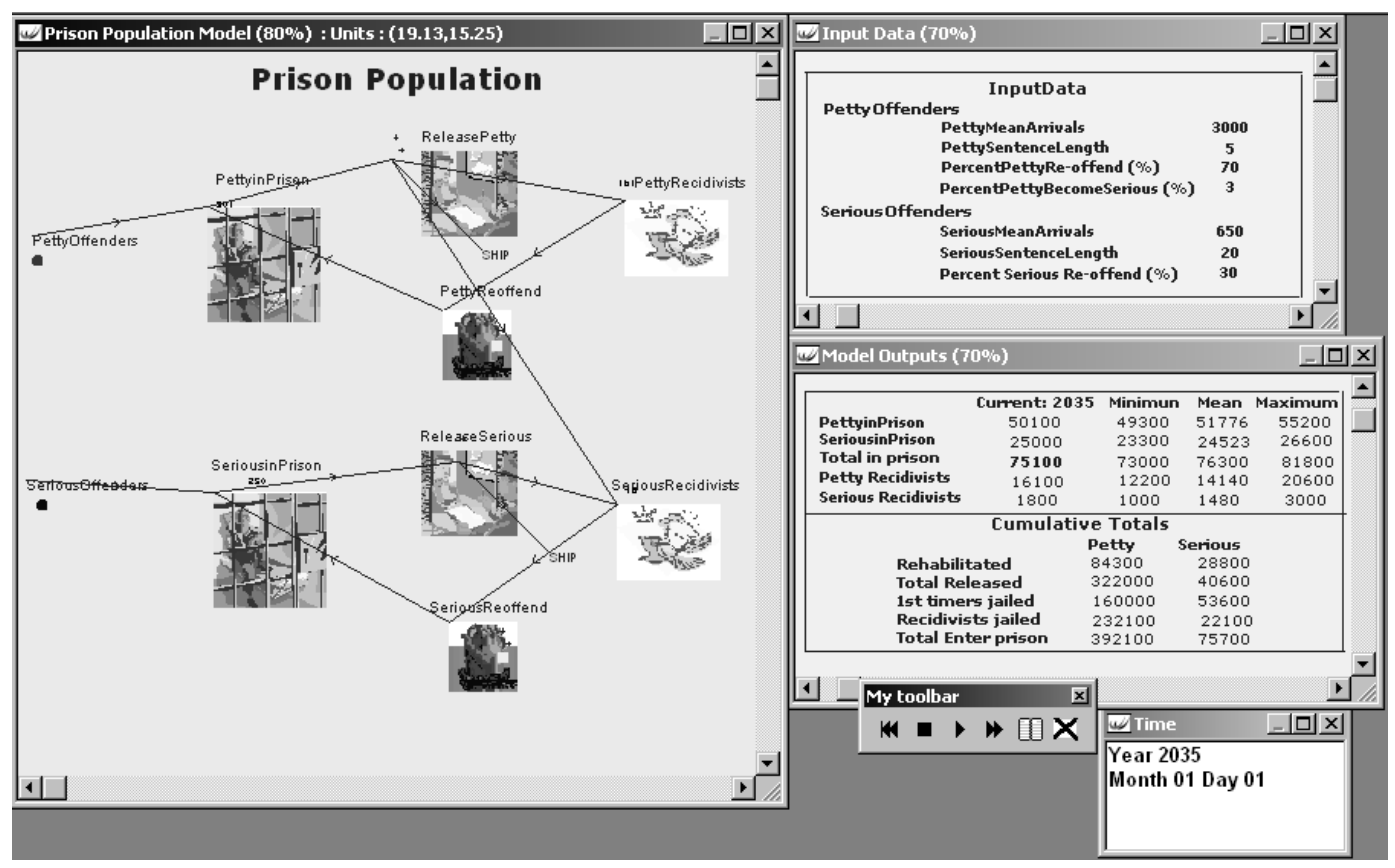

Figure 2: DES model representation in Witness, with the model on the left-hand side, input criteria in the top box on the right and in the box below model outputs.

In the DES model, entities enter the system and two attributes are set, "sentence length" and "time to re-offend". The entities then go straight to queues which represent the prison population, either as "PettyinPrison" or as "SeriousinPrison". In these queues they serve time according to the attribute "time in prison". Prisoners then go into the release activity ("ReleasePetty" or "ReleaseSerious") from where they are either rehabilitated and exit the system ("Ship") or go to the recidivist queues, ("PettyRecidivists" or "SeriousRecidivists") according to the crime they have committed. In the recidivist queues the entities stay according to the attribute "time to re-offend" and then go to the re-offend activities ("PettyReoffend" or "SeriousReoffend"), where the attribute "sentence length" is reset. From there the entities re-enter the prison population.

The SD model consists of 4 different pages: introduction, control panel, prison population diagram and the main model. The pages are linked via hyperlinks so that users can easily navigate from one page to the other. The SD model representation is 
shown in figure 3. Two separate flows, petty and serious admissions enter the system and go straight into the prison population stocks ("Petty criminals in prison" and "Serious criminals in prison"). Prisoners flow out of prison through the outflows, ("Petty Release rate" and "Serious release rate") to the stocks "Released petty" and "Released serious". Prisoners leave the released prisoner stocks either as rehabilitated prisoners or reoffenders, the latter creating a feedback loop to the prison population stocks. The stock "Released petty" has an additional outflow, "Become Serious", which takes a small part of the released prisoners straight to the stock "Serious criminals in prison". The feedback structure, typical of SD models, is evident in the flows of released and reoffending prisoners.

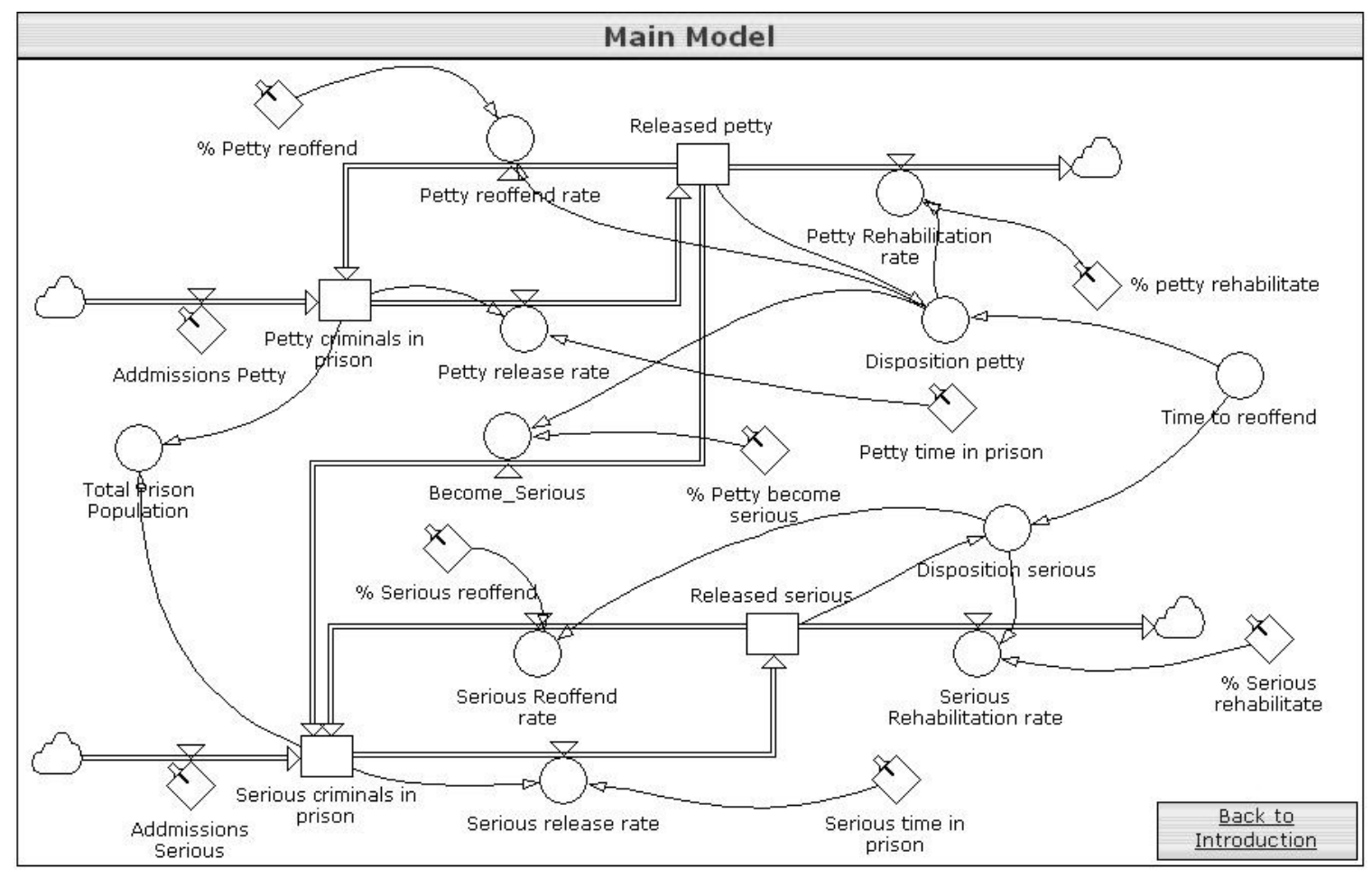

Figure 3: SD model representation in Powersim.

The Control Panel (figure 4) is the main working environment where users can interact with the model and enter inputs according to their choice of policy or policies and observe relevant outcomes. The control panel consists of two parts. The user interface includes a set of sliders for the prison admission rates and the sentence time, and three combo boxes which provide choices for the percentage of re-offending. Next to the user interface are the model Results, which consist of a set of graphs and tables of key outputs that are simultaneously updated. 

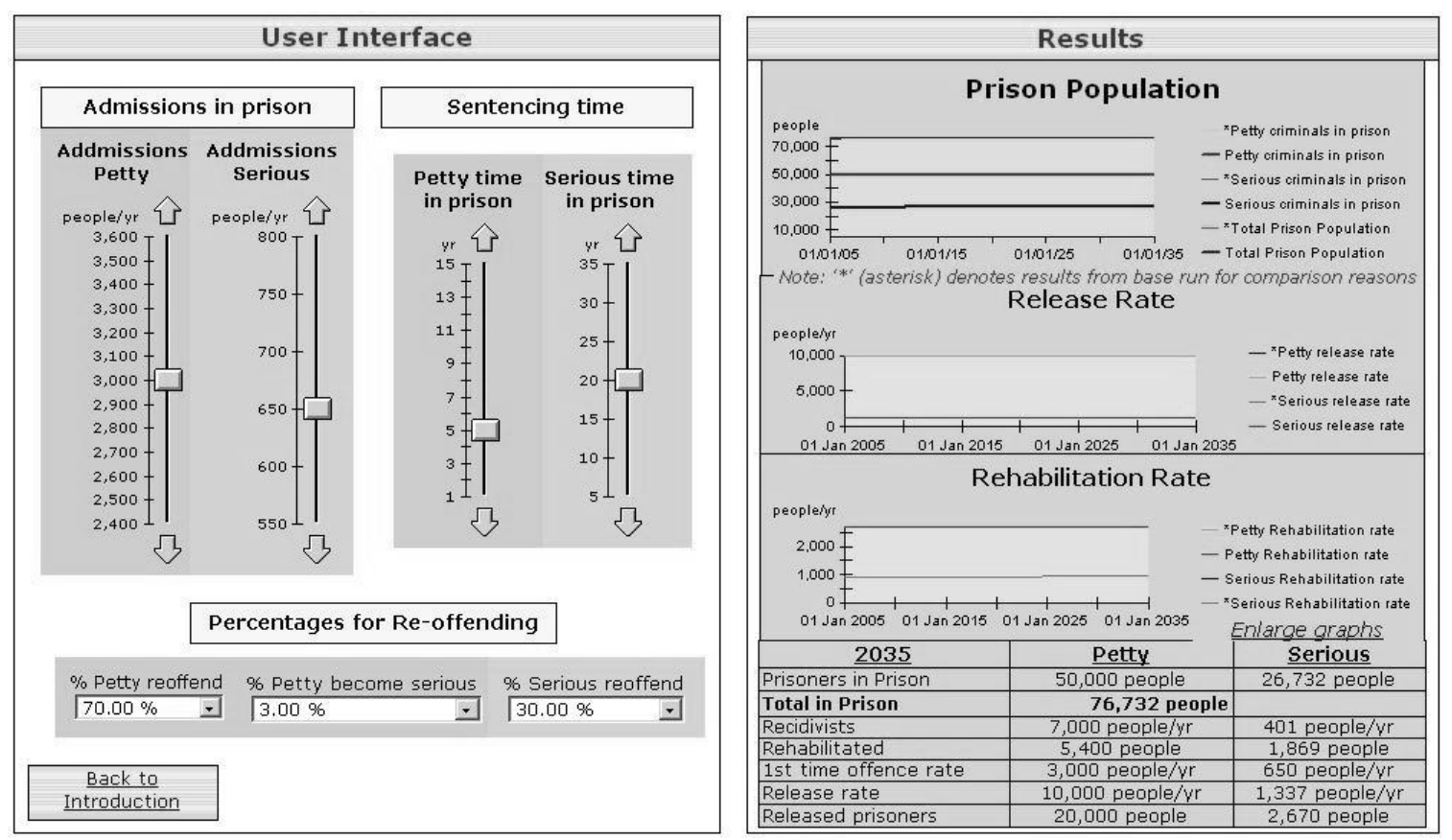

Figure 4: SD model Control Panel, which included the user interface and model results page. This was the main working environment.

Some key differences can be observed in the DES and SD models presented above. In the DES model the entities are individually represented and specific attributes assigned to them, i.e. sentence length, offender type, number of times incarcerated etc. Due to the large number of entities the run speed of the model becomes very slow and so the numbers have been scaled down to a fraction of $1 / 100$, where 1 entity represents 100 offenders. Grouping entities is a well known practice in DES modelling (Robinson, 2004). Therefore, it can be claimed that there is some level of aggregation involved in the DES model. However, the main feature of DES, which enables the tracking of entities (in this model the group of 100 prisoners) and their attributes is still present. After all, one of the main reasons DES is chosen in practice is its capacity to track individuals in the system.

On the other hand, in the SD model the entities are presented as a continuous quantity, where state changes happen continuously at small segments $(\Delta t)$ of time. In the SD model, the time-step $(\Delta t)$ used is 1 year. Specific entities cannot be followed through the system. Therefore, it can be claimed that there is a higher level of aggregation in the SD model than in the DES model. Modelling the large number of people in the system did not require any specific handling in SD, which is naturally suited to dealing with large populations. 
Key variables in the DES model are sampled using the exponential or Erlang distributions, e.g. admissions to prison, time to re-offend and sentence length. In this way randomness is incorporated into the model. On the contrary, in the SD model these same variables are represented as deterministic average values.

Another fundamental difference in the two model representations is related to how the initial number of people already in the system is set up. Powersim and all SD software packages have a facility for setting up the initial stocks at the beginning of the simulation run. In Witness, however, there is no such facility for queues. Two options were available. The model could be run for a warm-up period to allow the system to fill-up to the desired level. The other option was to create dummy entities which enter the model at the start of the simulation run and are assigned to the various queues. The latter option was considered more appropriate, as a warm-up period would have added significantly to the run time of the model and it would have been less intuitive for the users. Because the DES model collects results on the individual entities, each dummy entity had to be given a history of when it had entered the model, otherwise the results would have been skewed. This was achieved by sampling negative times of entry.

A conceptual difference between the two models is the way that released prisoners were dealt with. In the DES model released prisoners who do not re-offend leave the system straight away after being released. In contrast, in the SD model all released prisoners are kept for 2 years in the released stocks and after that a proportion of the stock flows out of the model. The difference arose because in the SD model it is necessary to accumulate all released prisoners into a stock before determining what happened to them next.

Regarding the data requirements, both models required almost the same data inputs. The DES model is a close representation of the existing real life system, with variables set (approximately) to the values as described in the case by Grove et al. (1998). However, in the SD model variables which do not exist in real life were created in order to represent intended behaviours. For instance, some variables were created such as disposition ("Disposition Petty" and "Disposition Serious"), in order to obtain the correct proportions of re-offending and rehabilitation. Disposition calculates the release rate for all prisoners at liberty who stay for two years in the stocks of released prisoners, before calculating the rates of re-offending and rehabilitation. In this respect, it seems that SD has more flexible structures. 
Despite the differences discussed here, both models depict almost similar behaviour and the key outputs are quite similar (table 2). There are probably some differences in variable definitions from one model to the other, and thus some differences in the results. For example in the DES model the cumulative number of released prisoners (petty and serious) is displayed in the outputs, while in the SD model the number of released prisoners (petty and serious) at liberty at a specific point of time is displayed. In addition, in the DES model the number of recidivists represents the number of released prisoners at liberty in the community who will re-offend at some point in the future. Whereas in the SD model this number represents the rate of re-offending, that is, the number of prisoners who re-offend annually. Despite these differences the two models can still be considered equivalent.

Table 2: Comparison of DES and SD models outputs.

\begin{tabular}{|l|c|c|}
\hline & DES outputs & SD outputs \\
\hline Petty in Prison & 50,100 people & 50,000 people \\
Serious in Prison & 25,000 people & 26,732 people \\
Total in Prison & 75,100 people & 76,732 people \\
Petty Recidivists & 16,100 people & 7,000 people/year \\
Serious Recidivists & 1,800 people & 401 people/year \\
Released Petty & - & 20,000 people \\
Released Serious & - & 2,670 people \\
Total Released petty & 322,000 people & - \\
Total Released Serious & 22,100 people & - \\
\hline
\end{tabular}

\subsection{The subjects}

In any organisation it is the managers who are the ultimate users of a simulation model, whether it be directly experimenting with the model or as recipients of the results. In the latter case the manager would normally interact with the model to, at least, gain some confidence in the results. Managers, therefore, were considered the most relevant participants for the purposes of this study. Since we had ready access to executive MBA students at Warwick Business School, these were chosen as the subjects of the study.

The executive MBA students at Warwick are highly representative of managers working in the public and private sector. They have on average 12 years of work experience (www.wbs.ac.uk/students/mba/learn/class-profile-mod.cfm accessed November 2007) and at the same time as studying are holding managerial positions in their organisations. During the first year of their studies they take a core module, 
Modelling and Analysis for Management (MAM) (Robinson et al., 2003), on which one of the authors (Robinson) teaches.

The study was implemented with two different groups of MBA students who took the MAM module at two different times, the first in June 2006 and the second in February 2007. The first group consisted of 57 participants, this group used the DES model. The second group was made up of 37 participants and evaluated the SD model.

\subsection{The sessions}

Before the sessions, the subjects were given the case study description to read in advance. The sessions started with a brief presentation introducing the case study, the basics of the simulation models and how they work. Two further sets of hand-outs were given, of which one was the model description and the other included guidance as to how to use each model. The participants were then divided into syndicated groups and were asked to work on the task for 30-40 minutes. During this time they were asked to take the role of the government consulting service and to identify solutions to the problem. The groups consisted of 4-6 participants. All group members were involved in group discussions. During the group session, the researchers (the authors) were roaming from group to group providing support for technical problems and answering questions about the case. A feedback session followed, where two random syndicate

groups for each session presented their findings and further discussions and comments were made by all participants. At the end, a questionnaire was handed out, which the participants were asked to complete and to return to the researchers.

\subsection{The questionnaire}

A two-page questionnaire was devised in order to explore the MBA students' views about the models. The questionnaire consists of two parts. The first part deals with the participants' job details and the second part with the participants' opinions about the simulation models used as part of the exercise. The main question format used for collecting the users' opinions on the models was the 5-point Likert type scale ranking from 1 to 5 , giving an ordinal, non-metric measurement. The 1 to 5 response scale is commonly used in social science research (Buckingham and Saunders, 2004). Other types of questions included are rank order/multiple-choice, single select (yes/no) questions and open-ended questions. 
This is an innovative study in the simulation area looking into managers' perceptions of DES and SD simulation models. We could not find any pre-conceived measures on simulation model use in the simulation literature. Therefore, we created the measures used here from our experience as modellers and the statements made in the literature concerning DES and SD. A pre-test was run with $5 \mathrm{PhD}$ students from Warwick Business School to check the clarity of the questions and the layout of the survey. As a result, some changes were made in the wording of some of the questions. The questionnaire dealt with participants' opinions in terms of: model understanding, model complexity, model validity, model usefulness and model results. We briefly explain below the questions included in the main body of the questionnaire. (The questionnaire is available on request to the authors.)

Questions regarding model understanding dealt with the extent that users feel they understand the model and parts of it. On model complexity, a set of questions focused on the users' opinions about the perceived level of detail in the models and also about the sources of complexity they discern. Questions on model validity dealt with the subjects' opinions about the extent to which they think the models are representative of the case study situation, that model outputs are realistic and about their confidence in using the model in decision making. The next question asked the participants to rate model usefulness in terms of learning, strategic thinking involved and communication of ideas. Concerning the simulation results we were interested to find out what type of data (numerical vs. graphical) users referred to when looking at the results. The aim was to find out what attitude the models induced when handling the results (instrumental vs. conceptual learning). The next question asked the users about the level of difficulty in interpreting the results, the use of graphs (and randomness associated with them) and about the way of thinking when looking at the results ("Do users look for the factors that cause changes in the results?" which is a characteristic attitude in the SD world).

\section{Survey results}

In this section the results of the statistical analysis on the data collected from the questionnaire survey are presented. Overall the empirical work does not identify significant differences for most of the comparison criteria for DES and SD model use.

In order to test for differences in users' opinions, non-parametric statistical tests are carried out due to the nature of the data obtained from the questionnaire (ordinal and nominal data). According to Siegel (1957) meaningful statistics for nominal data are 
frequency counts and the mode, and for ordinal data, the median. Diagnostic P-P (probability-probability) plots are used to graphically explore differences in the distributions of ordinal data comparing answers received from the two groups of users. Fisher (1983) and Law (2007) suggest the use of P-P plots in order to compare two distributions. When the plot is linear or close to linear, the two distributions of answers fit one another, meaning that the variables have identical distributions (Wilk and Gnanadesikan, 1968; Fisher, 1983; Law, 2007). The chi-square test for the nominal data and the Mann-Whitney-Wilcoxon test (Fisher, 1983; Siegel, 1988) for the ordinal data are used to check that the differences are statistically significant.

\subsection{Respondents profiles}

From the questionnaire survey with 2 different groups of executive MBA students, 34 usable questionnaires were derived from the DES group (implemented in June 2006) and 30 from the SD group (implemented in February 2007). This gave response rates of $65 \%$ and of $79 \%$ respectively. The participant groups were two mixed groups of executive MBA students in terms of background and management level.

Considering the industry sector participation in the survey sample (table 3), the majority of the DES group came from the public services sector (32\% - 11 respondents) and from Manufacturing (21\% - 7 respondents), whereas the SD group, had no representation from the public services. We can argue that participants from the public services sector are more familiar with problems in the prison population case study and so the DES group could be considered more predisposed to the exercise and the models. The majority of the respondents in the SD group came from the manufacturing sector (40\% - 12 respondents). There was a smaller representation of the other sectors in both groups.

Table 3: Sample representation by industry sector

\begin{tabular}{|l|c|c|}
\hline Industry & DES group & SD group \\
\hline Public Services & $32 \%$ & - \\
Manufacturing & $21 \%$ & $40 \%$ \\
Business Services & $18 \%$ & $13 \%$ \\
Financial Services & $9 \%$ & $3 \%$ \\
Transport \& Communic. & $9 \%$ & $13 \%$ \\
Energy \& Mining & $6 \%$ & $13 \%$ \\
Trade & $3 \%$ & $3 \%$ \\
Construction & $3 \%$ & $3 \%$ \\
Other & - & $10 \%$ \\
\hline
\end{tabular}


Respondents were also asked to indicate their functional areas and their position in the management hierarchy. Participants in the DES group consisted of $34 \%$ working in the production/operations area, $20 \%$ in sales \& marketing and $9 \%$ in computing/IT services, with a lower representation from finance, procurement, R\&D and customer services. A somewhat similar picture was observed in the SD group, with $23 \%$ of respondents working in the production/operations area, $27 \%$ in sales \& marketing, and $13 \%$ in computing/IT services and a lower representation of the other areas.

Regarding the participants managerial level (table 4), the majority of the DES group $(61 \%)$ came from the lower (line) manager level with higher and middle management having a lower representation. Meanwhile, the SD group had a somewhat different representation, with the proportions being $40 \%$ and $47 \%$ for middle and lower level management respectively, while higher management had a lower representation. This suggests that both groups had a somewhat different mix regarding managerial level, which might affect the answers and thus the results. However middle and line managers counted together represented $88 \%$ of the DES group and $87 \%$ of the SD group. Having a high representation of line management positions in both samples is considered to be beneficial for the survey. The authors believe that managers of a lower level tend to use simulation to a higher extent as a problem solving tool. In fact, considering both groups together (table 5), line managers made up the majority of respondents with prior experience 12 (out of 18 ) and only 4 (out of 18) middle managers had prior experience (table 5). There was only one instance of a higher level manager with prior experience of simulation.

Table 4: Managerial level for each group

\begin{tabular}{|l|c|c|}
\hline Management level & DES group & SD group \\
\hline Executive & $12 \%$ & $10 \%$ \\
Middle management & $27 \%$ & $40 \%$ \\
Manager & $61 \%$ & $47 \%$ \\
Other & - & $3 \%$ \\
\hline
\end{tabular}


Table 5: Prior experience by management level (includes both DES and SD samples)

\begin{tabular}{|l|cc|}
\hline Management level by & \multicolumn{2}{|c|}{ Count } \\
\cline { 2 - 3 } prior experience & No & Yes \\
\hline Executive & 5 & 1 \\
Middle management & 17 & 4 \\
Manager & 21 & 12 \\
Other & 2 & 1 \\
\hline Total & $\mathbf{4 5}$ & $\mathbf{1 8}$ \\
\hline
\end{tabular}

\subsection{Comparing the level of understanding using the DES and SD model}

The respondents were given a series of statements regarding their understanding of the models when using either the DES or the SD model. Understanding deals with: overall model understanding, understanding of the relationship between variables, understanding of the model structure, understanding of how to use the model and understanding of the model outputs. The level of understanding for each of these items is measured on a scale of 1 to 5 , where 1 means "understand very little" and 5 means "understand very well". The aim here was to measure the users' opinions about their understanding of the simulation model and parts of it and then to compare the answers from both groups.

The P-P plots reveal differences in DES and SD model users' opinions only for the variables: understanding of the relationship between variables and understanding of how to use the model (figures 5 and 6). The P-P plots consist of 5 data-points, where each dot represents the cumulative probability for each Likert scale measure $(1=$ understand very little, up to level $5=$ understand very well), with 1 on the left and 5 on the right. The DES probabilities are plotted on the x-axis and for SD on the y-axis.

Looking more closely at both graphs we can observe that the lines are skewed towards the DES model. This means that the DES model users gave a higher proportion of responses in the mid-range (understand little, moderate and understand well, levels 2 , 3 and 4), while the SD model was mostly rated at the higher levels of the scale (levels 3 , 4 and 5). This implies that SD model users perceived that they had a better level of understanding regarding the relationship between variables and how to use the model. The Mann-Whitney-Wilcoxon test, however, does not identify these differences as significant.

In the P-P plots for the other items on understanding (overall understanding of the model, understanding its structure and understanding of the model outputs) there is little 
difference between the two groups. This is confirmed by a lack of statistical significance in the differences as well.

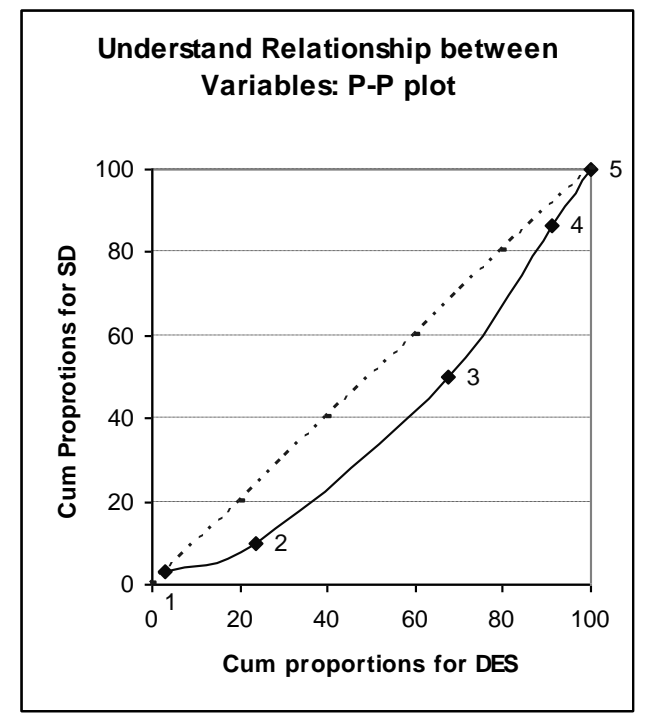

Figure 5: P-P plot on understanding of the relationship between variables, SD vs. DES answers, where 1 means understand very little and $\mathbf{5}$ understand very well.

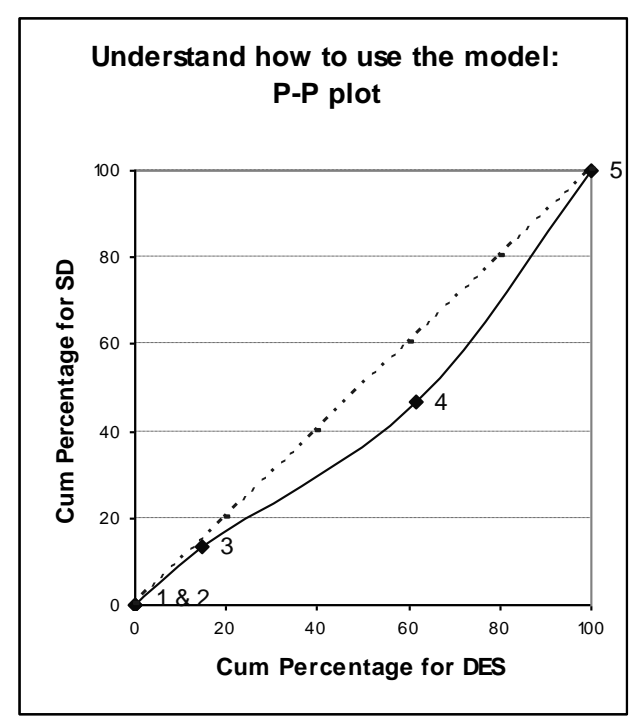

Figure 6: P-P plot on understanding of how to use the model, SD vs. DES answers, where 1 means understand very little and 5 understand very well. Points 1 \& 2 coincide with the origin of the coordinates $(0,0)$ because none of the respondents answered with: understand very little, and little, for either model. 


\subsection{Factors that help in model understanding}

The question regarding the factors that help model understanding asked the user to rank in order of importance the factors: paper-based material, visual display of the model and animation as the model runs. Looking at the answers received for each factor in table 6 , there is a clear difference in the rankings of the DES group and the SD group for the factors paper-based description and animation as the model runs. This shows that the DES group identified animation as the most important factor that aided model understanding (58.8\%), followed by the paper-based description as very important (55.9\%). Meanwhile, the SD group identified the paper-based material as the most important factor (62.1\%). However, there is no clear difference in the two groups' rankings regarding the visual display of the model. DES and SD users equally rated it as the least important factor.

Table 6: Ranking of factors that helped user understanding of the models (DES \& SD)

\begin{tabular}{|l|l|c|c|c|}
\hline \multicolumn{2}{|l|}{ Factor by model type } & $\begin{array}{c}\text { Important } \\
(\%)\end{array}$ & $\begin{array}{c}\text { Very important } \\
(\%)\end{array}$ & $\begin{array}{c}\text { Most important } \\
(\%)\end{array}$ \\
\hline \multirow{2}{*}{$\begin{array}{l}\text { Paper-based } \\
\text { material }\end{array}$} & DES & 17.6 & 55.9 & 26.5 \\
\cline { 2 - 5 } & SD & 10.3 & 27.6 & 62.1 \\
\hline \multirow{2}{*}{ Visual display } & DES & 73.5 & 20.6 & 5.9 \\
\cline { 2 - 5 } & SD & 75.9 & 17.2 & 6.9 \\
\hline \multirow{2}{*}{ Animation } & DES & 11.8 & 29.4 & 58.8 \\
\cline { 2 - 5 } & SD & 24.1 & 48.3 & 27.6 \\
\hline
\end{tabular}
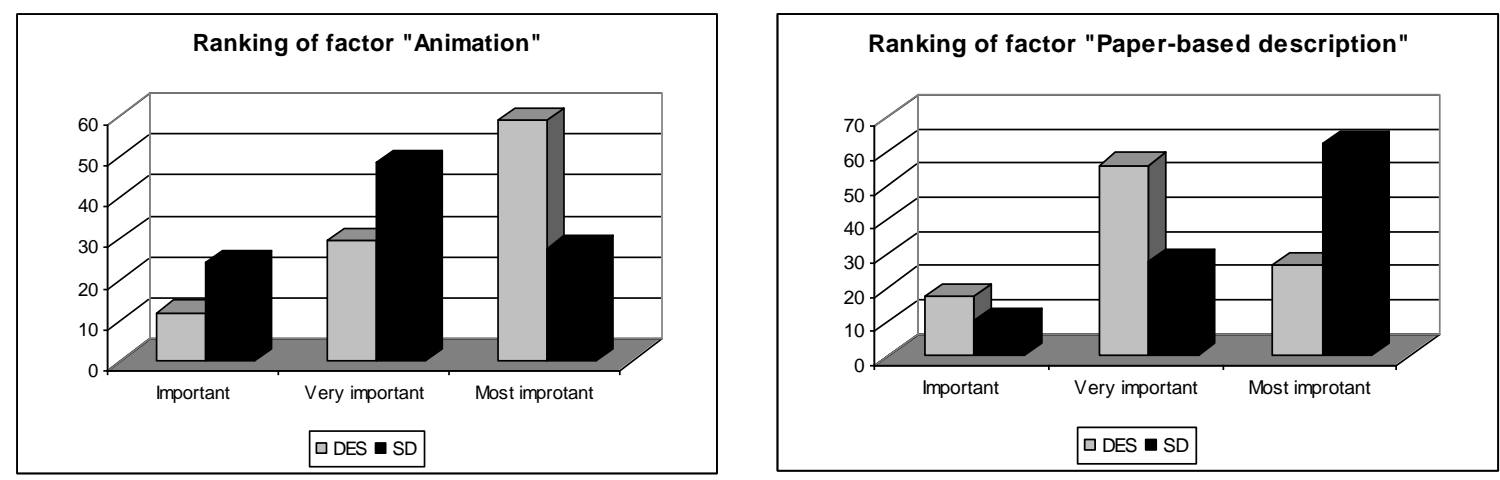

Figure 7: Frequency diagram showing importance of animation and paper-based description as factors that helped user understanding of the model (DES \& SD)

We draw attention here to figure 7 which shows the differences between the two groups regarding the factors animation as the model runs and paper based material. The 
Mann-Whitney-Wilcoxon test shows that there is indeed a significant difference in users' opinions regarding these factors at a $1.4 \%$ and $2.9 \%$ significance respectively. This suggests that for the DES model animation has the greatest impact in helping model understanding, while for the SD model the paper-based material has most effect.

\subsection{Model complexity}

Concerning the level of detail, a Likert-type question asked the user to rate the simulation models, where, 1 represents very detailed and 5 a very high level perspective. The P-P plot in figure 8 reveals a skew towards the SD model, with the SD model having a higher proportion of answers at the lower level of the scale, corresponding to a greater level of model detail. This is the opposite of what we expected since it is generally thought that DES models are more detailed (section 2.2).

The users could have perceived the SD model as more detailed due to the fact that all the components of the SD model are explicitly presented on screen (as per figure 3), whereas for the DES model the structure may not be so explicit (figure 2). The actual relationships between variables in DES models are not so apparent to the users when compared to SD models where the stocks, flows and auxiliary variables are displayed on the screen. Despite some skew towards the SD model results in the P-P plot (figure 8), the chi-square and Mann-Whitney-Wilcoxon tests do not reveal any significant differences between the two samples.



Figure 8: P-P plot on level of detail of the model, SD vs. DES answers, where 1 means very detailed and 5 meant very high level. 
Next the questionnaire consisted of an open-ended question asking the users to identify the sources of complexity in the model. The aim was to find out how obvious the feedback in each model (DES and SD) is to both groups of survey participants, without specifically mentioning 'feedback' in the question. It should be noted that the students had received no instruction on feedback as part of the MBA module. We hoped the users would identify the feedback in the model by considering the complexity that arises due to prisoners re-entering prison. Only $20 \%$ of the DES group answers and only $3 \%$ of the SD group answers are found as correct. Correct answers are considered as those that refer to the relationship and the interdependency between variables or to reoffending. A chi-square test reveals a significant difference in the proportions between the two groups, with a chi-square value $\chi=4.33$, significant at $3.7 \%$ level. Contrary to what we were expecting, this suggests that the feedback effects are more explicit to the DES model users as compared to the SD model users.

One possible reason for this counterintuitive result might be because the users did not actually explore the models enough in order to pick up on their underlying features. In the case of the SD model, the users would not be able to pick up the feedback effects between variables unless they navigated to the model representation page. We are cautious, however, about this finding due to the low response rate to this question (the response rate was $35.3 \%$ for the DES group and $13.3 \%$ for the SD group).

\subsection{Model validity}

In terms of model validity, a section of the questionnaire dealt with whether the user found the models to be representative and the outputs realistic. It also asked about the user's confidence in the models. The P-P plots do not show a difference between the two groups, apart from the plot on model representativeness. Observing the P-P plot in figure 9, the data are skewed towards the DES group, revealing that the users of the DES model rated it as being representative at lower levels, mostly levels 2 and 3 (little and moderate respectively), while SD model users rated the model higher, mostly levels 3 and 4 (moderate and much). This implies that the SD model was perceived to be more representative of the case study compared to the DES model. Furthermore, a MannWhitney-Wilcoxon test identifies a somewhat significant difference at a $6.5 \%$ level.

When performing a Mann-Whitney-Wilcoxon test on the answers of just users with no prior experience of simulation models, there is a more significant difference between the DES and SD groups; significant at the $1.7 \%$ level. This finding suggests that, for users 
with no prior simulation experience, the SD model was perceived to be more representative of the case study as compared to the DES model. An obvious reason for this result could be that, as discussed above, the SD model structure is more explicit than the DES model structure. One DES model user commented that they would be interested to see the underlying maths.

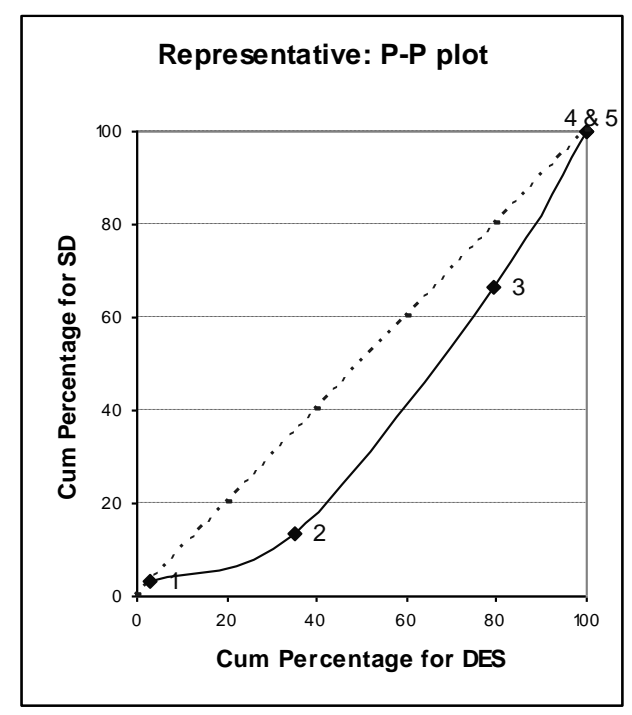

Figure 9: P-P plot on model representativeness, SD vs. DES answers, where 1 means very little and 5 very much. Points 4 and 5 coincide because none of the respondents considered the models representative at level 5 .

\subsection{Model usefulness}

In a separate section, three Likert-type questions and 1 open-ended question were used to reveal users' opinions regarding the usefulness of the two simulation models. The Likert-type questions asked users to express their opinions about whether the use of the models enhanced their learning, whether it helped them think about the problem and whether it facilitated the communication of ideas. Next, with an open-ended question we asked the participants to identify systems that are similar to the context of the prison population model. This question aimed to identify whether after using the prison population model the participants could transfer the knowledge gained to other similar systems. "Knowledge transfer" can be used as an indicator of the learning achieved (Morecroft and Sterman, 1994). 
The P-P plots do not identify any differences in the responses to the Likert-type questions apart from the question as to whether the use of the models facilitates the communication of ideas. In the P-P plot in figure 10, the line is skewed towards the SD axis in the lower levels of the scale. Here the users rate mostly high and very high the DES model in facilitating the communication of ideas. The Mann-Whitney-Wilcoxon test, however, does not identify any significant differences for the 3 Likert-type questions.



Figure 10: P-P plot on the capacity of the model to facilitate the communication of ideas, SD vs. DES answers, where 1 means very little and 5 very well.

As for the open-ended question, only $23 \%$ of responses from each group are considered as appropriate answers to the question. Examples of correct answers are hospital/bed occupancy and social (unemployment) services. This indicates that the same level of learning was achieved by both groups. However, we are cautious about our findings here because there was a high level of no-response to this question (the response rate was $44 \%$ and $36.6 \%$ for DES and SD group respectively). On the other hand, it is not clear why some participants did not answer this question. It might be that no-answer reflected a lack of learning and so a lack of ability to transfer the knowledge gained.

\subsection{Model results}

In terms of model results, an issue of importance is the type of results users look at when running a simulation model. DES model users were expected to focus on "instrumental learning" and so were expected to look more at numerical data. 
Meanwhile SD model users were expected to use graphs to a higher extent with more of an interest in "conceptual learning".

The questionnaire results show that, almost the same proportion of participants from both groups used the numerical results (instrumental learning). On the other hand, a higher proportion of respondents in the SD group claimed to have used the graphs (conceptual learning) as compared to the DES group. The bar chart in figure 11 reveals the differences in the level of use of graphs between the two groups. Indeed, a relaxed chi-square test reveals a significant difference between the two groups at a $9.2 \%$ level of significance.

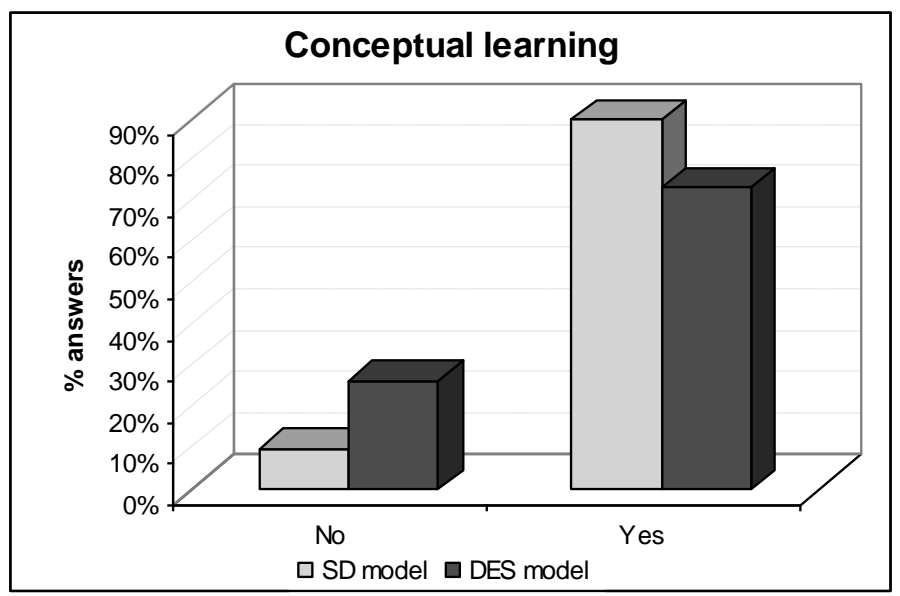

Figure 11: Bar chart with frequencies of DES \& SD model users who used graphical outputs (conceptual learning) - a higher proportion of SD model users.

The rest of the questions dealt with the user's perceived difficulty in the interpretation of results, the usefulness of graphs and the examination of factors that cause differences in the results. The data reveal a difference in the two groups' opinions regarding the difficulty in the interpretation of results. The P-P plot in figure 12 is significantly skewed towards the SD model, meaning that SD model users found the results interpretation less difficult. Also a Mann-Whitney-Wilcoxon test reveals a significant difference at the $3.6 \%$ level. 


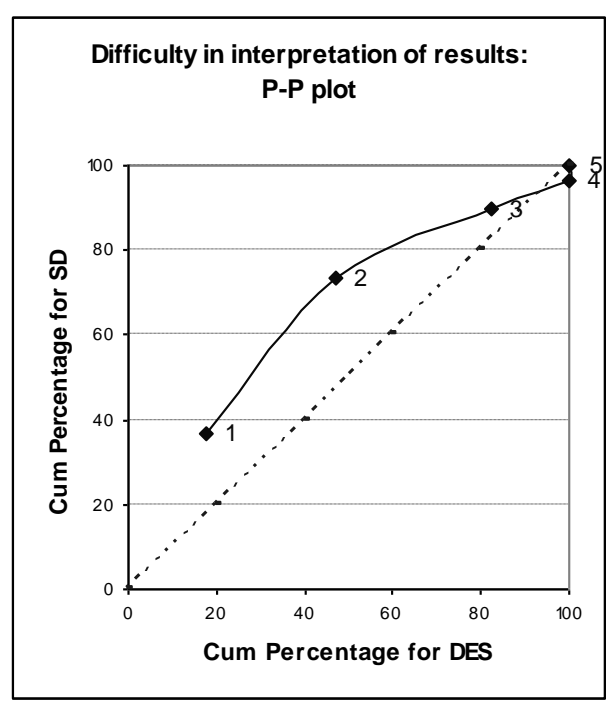

Figure 12: P-P plot on perceived difficulty in the interpretation of model results, SD vs. DES answers, where 1 means very straightforward and 5 very difficult.

Regarding the users' attitude when interpreting the model results, an open-ended question asked the user to identify what is the main learning from the graphs and whether the user tried to identify the factors that cause changes in the outputs. These questions are intended at finding whether the two models trigger model users to employ different attitudes towards model results. It was expected that DES model users would take notice of the randomness present in the outputs, and therefore in response to the question they would mention randomness as their main learning point from the graphs. In the case of the SD model, the users were expected to be looking for the endogenous factors that cause the changes in the variables' behaviour. However, from the responses received there is no evident difference between the two groups of users regarding their attitude to interpreting the results.

\subsection{Summary of results}

A summary of the main findings derived from the questionnaire is presented in table 7. 
Table 7: Summary of results comparing DES and SD model use

\begin{tabular}{|c|c|c|}
\hline Model Use & DES & SD \\
\hline \multicolumn{3}{|l|}{ Model Understanding } \\
\hline $\begin{array}{l}\text { Level of understanding the } \\
\text { model (and parts of it) }\end{array}$ & \multicolumn{2}{|c|}{ No differences identified in users' opinions } \\
\hline $\begin{array}{l}\text { Factors that helped } \\
\text { understanding }\end{array}$ & $\begin{array}{l}\text { Animation the most important } \\
\text { factor }\end{array}$ & $\begin{array}{c}\text { Accompanying model } \\
\text { descriptions is most important }\end{array}$ \\
\hline \multicolumn{3}{|l|}{ Complexity } \\
\hline Level of detail & \multicolumn{2}{|c|}{ Similar level of perceived detail } \\
\hline Feedback & $\begin{array}{c}\text { Feedback effects more explicit } \\
\text { to DES model users }\end{array}$ & \\
\hline \multicolumn{3}{|l|}{ Model validity } \\
\hline $\begin{array}{l}\text { Representative of real } \\
\text { problem }\end{array}$ & & $\begin{array}{c}\text { SD model just more representative } \\
\text { as compared to DES model }\end{array}$ \\
\hline Realistic outputs & \multicolumn{2}{|c|}{ Outputs are perceived similarly realistic } \\
\hline Confidence in outputs & \multicolumn{2}{|c|}{ Similar level of confidence in model outputs } \\
\hline \multicolumn{3}{|l|}{ Model usefulness } \\
\hline Learning & \multicolumn{2}{|c|}{ Similar level of learning achieved from using DES and SD models } \\
\hline Strategic thinking & \multicolumn{2}{|c|}{ Same level of perceived strategic thinking involved } \\
\hline Communication of ideas & \multicolumn{2}{|c|}{ Same level of communication perceived to have taken place } \\
\hline \multicolumn{3}{|l|}{ Model results } \\
\hline \multirow{2}{*}{$\begin{array}{l}\text { Instrumental/ conceptual } \\
\text { learning }\end{array}$} & \multicolumn{2}{|c|}{ Both SD and DES aid instrumental learning } \\
\hline & & $\begin{array}{c}\text { SD model aids conceptual learning } \\
\text { to a higher extent }\end{array}$ \\
\hline Interpretation of results & $\begin{array}{l}\text { DES model results were } \\
\text { more difficult to interpret }\end{array}$ & \\
\hline $\begin{array}{l}\text { Attitude when interpreting } \\
\text { results }\end{array}$ & \multicolumn{2}{|c|}{ No differences in the users' attitude } \\
\hline
\end{tabular}

Understanding, defined as the users' opinion on the level of understanding gained from using the two simulation models, is not found to be significantly different for the two (SD and DES) groups. Some differences are observed regarding the factors that help users understand the model and parts of it. Animation is found as the factor that mostly aids model understanding for the DES group, while for the SD group it is the paperbased description of the model. This complies with the views of Sweetser (1999) and Morecroft and Robinson (2005) that animation and on-screen displays can help model understanding. However, our results suggest that the understanding gained from using a DES model (because of animation and on-screen displays) is not necessarily more than the understanding achieved when using a SD model. Even though, these findings suggest that the level of user understanding is the same, it can be argued that users gain different insights from the two models. However, observation of the DES and SD groups using the models suggests that this was not the case in the current study, because similar issues and policies were considered by both groups during their 
discussions. The case and accompanying materials were, of course, the same for both sets of users, and so this is not unexpected.

For complexity it is found that users from both groups rated the two simulation models as having a similar level of detail. A counterintuitive finding of this study is that the feedback effects are found to be more explicit to the users of the DES model. Contrary to the general belief that SD is more appropriate in representing feedback structures (Coyle, 1985; Sweetser, 1999; Morecroft and Robinson, 2005), DES can represent feedback effects, which in this case appear to be more explicit to the user. However, we are cautious about this finding because of the small number of answers received to the open-ended question on model complexity. Another issue to be considered is the subjectivity in the choice of the two model representations. The DES and SD models could have been represented in many different ways. We were, of course, only able to choose one mode of display for each model.

Regarding model validity, this study suggests that the extent to which the users perceive the models to be representative of the case study is different between the two groups. The SD model is found to be just more representative. For both models the outputs are perceived to be equally realistic and both groups of users had the same level of confidence in them. The higher level of perceived representativeness related to the SD model can probably be attributed to the overall picture of the system provided with the SD model representation. On the other hand, the finding that model outputs and the confidence in the model are equally rated by both groups implies that overall the level of users' acceptance of both models is not different.

Model usefulness is not identified as different between the two models. Against generally accepted opinions (Sweetser, 1999), the findings suggest that both simulation approaches can be used as learning tools and can both trigger the communication of ideas. Even though in the SD literature a range of examples exists that illustrate the use of models for learning and for the communication of ideas (Vennix 1996; Sterman, 2000), there are also cases where DES models have been used in facilitating group discussions and problem understanding (Robinson, 2001; 2002).

For model results the findings indicate that the users of both the DES and SD models use the numbers (numerical displays) to the same extent. Meanwhile, the SD users focus on graphical displays more than the DES users, suggesting that SD models can aid conceptual learning and thus help users look at the bigger picture. Regarding the level of difficulty in the interpretation of results, our findings support the literature 
(Brailsford and Hilton, 2001) that the DES model results are more difficult to interpret, even though this specific model and the results were fairly simple. No differences are identified in the users' opinions about the use of graphs and in the attitude employed by the users when interpreting the model results. However, a difference in attitudes was observed by the researchers during the group discussions. The SD model users tended to take a "goal seek" approach, where they blindly changed the inputs in order to get the right output, and then reflected on what policies might be employed to achieve these inputs. The DES group did not employ the same approach and focused on the effect a policy might have on the inputs to the model and then set the input values accordingly.

\section{Discussion and concluding remarks}

The current study adds to the discussion on the comparison between DES and SD. To the best of our knowledge this is the only empirical study that tests the differences in using DES and SD simulation models. The survey presented provides empirical evidence about how users' perceive the differences between DES and SD. The comparison criteria used in the survey are based on the generally accepted opinions/statements regarding the differences in using DES and SD found in the literature. Overall, it was not possible to identify many significant differences in the users' opinions regarding the specific DES and SD models used. This may imply that from the user's point of view the type of simulation approach used makes little difference if any. Akkermans (1995) reaches a similar conclusion, identifying that clients are usually indifferent to the simulation language being used. This may not be too surprising, as users are likely to be more interested in what they can learn from a model than about how the model works; that is, as long as the modelling approach is able to address the problem situation. However, we do need to consider whether this is a general conclusion or whether it is a result of some limitations in the validity of the study.

The participant groups involved in the exercise were two mixed groups of executiveMBA students in terms of background and level of management and thus comparable to each-other. There was a high representation of first line managers, who tend to be more involved in simulation projects, as compared to higher level managers. It should be noted that from the sample used in this study, the proportion of participants with no prior experience was higher than those with prior experience. Both groups commented on the simplicity of the models, but at the same time they appreciated their usefulness for the purpose at hand. Participants tended to be looking for more sophisticated models, 
considering a wider range of factors such as: costs, deaths, and other types of sentences.

In the current study, we used the best possible samples to which we had access at the time. Of course, the study could be improved with larger samples. In the DES group the highest proportion of participants had a background from public services and manufacturing, while in the SD group, manufacturing had the highest proportion. In the latter group there was no representation from the public sector. As a general comment, the DES group expressed a greater interest in the exercise, especially because it was a problem related to their jobs for a reasonable proportion (32\%) of the group. This in itself could have biased their answers. It would be considered a more fair experiment if the participants were randomly allocated into each group. However, random assignment of participants in the two groups was not possible because each MBA group took the same course at different times (May 2006 and February 2007) and it would have been difficult to present both simulation models to people with little or no prior experience of using simulation in a session of 1.5 hours. It was observed that because the users were exposed to only one of the two simulation models, they tended to take for granted the features of each simulation model, and did not pick up the specific features of each approach, which differ from one another. A solution to this would be to get the participants to work with both simulation models. However, this was not possible due to the limited amount of time available.

There is some level of subjectivity in the choice of the case study and the simulation models. The case study was chosen because it was amenable to both DES and SD modelling. Use of an alternative case study may have provided different findings in terms of the comparison of DES and SD. Meanwhile, a specific DES and a specific SD model were built of the prison population problem. These were only one representation in each approach out of many (if not an infinite number of) possible representations. Would different DES and SD models of the problem have led to different findings? To mitigate this effect, the DES and SD models were developed with the help of experts in their respective fields. It is believed that these models are typical DES and SD models, but it cannot be claimed that they are the only possible models.

Future work could compare DES and SD using different case studies, and a range of different models and simulation packages could be investigated for each case study. The authors of this paper are also studying the differences in terms of model development, involving experts from both simulation modelling approaches. The 
comparison in this case deals with the concepts and stages that DES and SD modellers go through when building simulation models. The authors intend to implement this study by "observing" participants while building simulation models (using DES or SD). It is expected that more significant differences between DES and SD will be found in the comparison of the model development process.

\section{References}

Akkermans, H. A. (1995). Modelling with Managers. Participative Business Modelling for Effective Strategic Decision-Making, PhD thesis, Technische Universiteit Eindhoven. Bard, J. F. (1978). The Use of Simulation in Criminal Justice Policy Evaluation. J Crim Justice 6(2): 99-116.

Brailsford, S. and Hilton, N. (2001). A Comparison of Discrete Event Simulation and System Dynamics for Modelling Healthcare Systems. In J. Riley (ed.) Planning for the future, Health Service Quality and Emergency Accessibility, Proceedings of the $26^{\text {th }}$ meeting of the ORAHS Working Group. Glasgow Caledonian University, Glasgow, Scotland.

Buckingham, A. and Saunders, P. (2004). The survey methods workbook: from design to analysis. Polity: Cambridge; Malden, Mass.

Cox, G. B., Harrison, P. and Dightman, C. R. (1978). Computer Simulation of Adult Sentencing Proposals. Eval Program Plann 1(4): 297-308.

Coyle, R. G. (1985). Representing Discrete Events in System Dynamics Models: A theoretical Application to Modelling Coal Production. J Oper Res Soc 36(4): 307-318.

Fisher, N. I. (1983). Graphical methods in nonparametric statistics: a review and annotated bibliography. Int Stat Rev 51: 25-58.

Forrester, J. W. (1961). Industrial dynamics. M.I.T. Press: Cambridge, Mass.

Grove, P., MacLeod, J. and Godfrey, D. (1998). Forecasting the prison population. OR Insight 11(1).

Korporaal, R., Ridder, A., Kloprogge, P. and Dekker, R. (2000). An analytic model for capacity planning of prisons in the Netherlands. J Oper Res Soc 51(11): 1228-1237. Kwak, N. K., Kuzdrall, P. J. and Schniederjans, M. J. (1984). Felony Case Scheduling Policies and Continuances - a Simulation Study. Socioecon Plann Sci 18(1): 37-43. 
Lane, D. C. (2000). You Just Don't Understand Me: Models of failure and success in the discourse between system dynamics and discrete event simulation. Working paper, 00.34:26.

Law, A. M. (2007). Simulation modeling and analysis. McGraw-Hill: Boston ; London. Mak, H.-Y. (1993). System dynamics and discrete event simulation modelling. PhD thesis, London School of Economics and Political Science.

Morecroft, J. D. W. and Robinson, S. (2005). Explaining Puzzling Dynamics: Comparing the Use of System Dynamics and Discrete-Event Simulation. In Proceedings of the 23rd International Conference of the System Dynamics Society, Boston.

Morecroft, J. D. W. and Sterman, J., Eds. (1994). Modeling for learning organizations. System dynamics series. Portland, Or., Productivity Press.

Pidd, M. (2004). Computer simulation in management science. Wiley: Chichester. Randers, J. (1980). Elements of the system dynamics method. M.I.T. Press: Cambridge, Mass.; London.

Robinson, S. (2001). Soft with a hard centre: discrete-event simulation in facilitation. $J$ Oper Res Soc 52(8): 905.

Robinson, S. (2002). Modes of simulation practice: approaches to business and military simulation. Sim Mod Practice and Theory 10(8): 513-523.

Robinson, S. (2004). Simulation: the practice of model development and use. Wiley: Chichester.

Robinson, S. (2008). Conceptual modeling for simulation Part 1: definition and requirements. J Oper Res Soc (Forthcoming)

Robinson, S., Meadows, M., Mingers, J., O'Brien, F. A., et al. (2003). Teaching OR/MS to MBAs at Warwick Business School: A turnaround story. Interfaces 33(2): 67-76.

Siegel, S. (1957). Nonparametric Statistics. Am Stat 13(3): 13-19.

Siegel, S. and Castellan, N. J. (1988). Nonparametric statistics for the behavioral sciences. McGraw-Hill: New York; London.

Sterman, J. (2000). Business dynamics : systems thinking and modeling for a complex world. Irwin/McGraw-Hill: Boston; London.

Sweetser, A. (1999). A Comparison of System Dynamics and Discrete Event Simulation. In Proceedings of 17th International Conference of the System Dynamics Society and 5th Australian \& New Zealand Systems Conference, Wellington, New Zealand. Vennix, J. A. M. (1996). Group model building: facilitating team learning using system dynamics. John Wiley: Chichester. 
Wilk, M. B. and Gnanadesikan, R. (1968). Probability plotting methods for the analysis of data. Biometrika 55(1): 1-17. 